En este artículo analizaremos uno de los ejes de la creación novelistica de Mario Vargas Llosa (la exploración del amor y el sexo) a través de las traducciones inglesas de las novelas Pantaleón y las visitadoras (1973), La tía Julia y el escribidor (1977), Elogio de la madrastra (1988) y Los cuadernos de don Rigoberto (1997). Si bien en casi todas las obras de Vargas Llosa el amor juega un papel relevante, en estas cuatro obras hay una fabulación explícita sobre la sexualidad humana y un notable trabajo sobre la elaboración lingüística y retórica del lenguaje del amor y el sexo. Traducir el lenguaje relativo al sexo es, sin duda, un área muy sensible, el lugar de confluencia entre las interdicciones sociales y los límites éticos de cada traductor.

PALABRAS CLAVE: Mario Vargas Llosa, lenguaje sexual, traducción, erotismo.

\title{
Amor y erotismo en Vargas Llosa \\ y su traducción al inglés
}

\section{Love and Eroticism in Vargas Llosa and its Translation into English}

José Santaemilia

Universitat de València
In this paper we analyze one of the key elements in Mario Vargas Llosa's fiction (the exploration of love and sex) through the Englishlanguage translations of his novels Pantaleón y las visitadoras (1973), La tía Julia y el escribidor (1977), Elogio de la madrastra (1988) and Los cuadernos de don Rigoberto (1997). Although love plays a fundamental role in all of Vargas Llosa's works, in these four novels there is an explicit creative effort around human sexuality and important linguistic and rhetorical elaboration of the language of love and sex. Translating sex-related language is a highly sensitive area, the site where the social interdictions and the translator's own ethics meet.

KEY WORDS: Mario Vargas Llosa, sexual language, translation, eroticism. 


\section{VARGAS LLOSA, AUTOR MUY POPULAR/ TRADUCIDO}

126 La obra narrativa de Mario Vargas Llosa muestra una amplia gama de temas, personajes o experimentos literarios. Es una obra extensa, profunda, rica en matices. Es, asimismo, una obra con difusión internacional, al haber sido traducida a multitud de idiomas, especialmente al inglés. En este artículo examinaremos uno de los pilares de la creación novelística de Vargas Llosa: la exploración del amor y el sexo. Y lo haremos analizando las traducciones inglesas de las novelas Pantaleón y las visitadoras (I973), La tía Julia y el escribidor (I977), Elogio de la madrastra (I988) y Los cuadernos de don Rigoberto (I997). Si bien en casi todas las obras de Vargas Llosa el amor juega un papel relevante, en estas cuatro obras hay una fabulación explícita sobre la sexualidad humana y un notable trabajo sobre la elaboración lingüística y retórica del lenguaje del amor y el sexo.

Con independencia del lugar que le corresponda en el conjunto de la literatura latinoamericana - y que determinarán los estudiosos de dicha literatura-, lo que sí podemos afirmar es que Mario Vargas Llosa ha sabido labrarse una imagen de autor mediático y popular, de máximo representante de las letras peruanas, de dandy, de liberal, etc. Aparece con frecuencia en la prensa de diversos países del mundo, tanto para presentar sus nuevas creaciones como para revisar su ya extensa obra. Podríamos decir que cultiva con esmero un refinado narcisismo de corte intelectual. Es, sin duda, un homme de lettres que participa sin cesar en la vida pública, ya sea a través de columnas políticas en periódicos prestigiosos, o de lecturas y representaciones de sus textos teatrales o poéticos, o de las crónicas de algunos de los principales conflictos políticos contemporáneos. Es, en suma, un homme- orchestre que aquilata una bien ganada reputación en la república mediático-comercial de las letras. La recepción de su obra en otras lenguas queda asegurada, además, por la traducción. Prácticamente todas las novelas de Vargas Llosa han sido traducidas al inglés, y por traductores tan prestigiosos como Helen Lane, Gregory Rabassa, Gregory Kolovakos, Ronald Christ, Alfred Mac Adam o Lysander Kemp. Contar con buenos traductores, que sean capaces de trasladar la fuerza del original, es garantía de la pervivencia de un autor. La no traducción de un autor a una determinada lengua constituye un vacío cultural importantísimo, pero las traducciones mediocres son el peor mal que puede aquejar a la futura transmisión de un autor en una determinada cultura. No es, desde luego, el caso de Vargas Llosa, que tanto en español como en inglés es un autor consolidado, un activo intercultural, un valor seguro para las editoriales que poseen los derechos de traducción ${ }^{\mathrm{I}}$.

\section{VARGAS LLOSA Y EL EROTISMO}

La obra de Mario Vargas Llosa, como la de todo gran creador, presenta muchas aristas y muy diversos niveles de lectura. Podemos centrarnos en su técnica narrativa, en la dimensión autobiográfica, en la violencia que inunda a todos sus personajes, en el contraste entre la alta cultura y la cultura popular, en las posturas ideológicas del autor, etcétera. Pero es, sin duda, la fabulación literaria en torno al amor

I Lo cual se manifiesta claramente en la distancia que separa la aparición de la obra original y la de la traducción. Por ejemplo, la última novela de Vargas Llosa, Memorias de la niña mala es de 2006, y su traducción al inglés, realizada por Edith Grossman, apareció en 2007. Los lectores británicos o estadounidenses de Vargas Llosa hubieron de esperar cinco años para poder leer Pantaleón y las visitadoras (I973) y La tía Julia y el escribidor (I977), y tres años para leer Elogio de la madrastra (I988). 
y al erotismo uno de los ejes de su creación literaria.

Para Olga Caro (1990: 167), es «innegable que la sexualidad tiene un papel determinante en la obra de Mario Vargas Llosa». El autor peruano considera el amor y el sexo elementos integrales de toda buena novela, de toda novela que aspire - como hacía su maestro literario, Flaubert- a reflejar la realidad. La vida rebosa erotismo, como rebosa también violencia, tragedia, frustración. Por ello, la mirada que Vargas Llosa lanza sobre los comportamientos sexuales humanos es, con frecuencia, uno de los principios organizadores de su quehacer novelístico. Esta expresión del erotismo es, asimismo, y a menudo, fuente de estilo. Aquí situaríamos los diminutivos, que en Vargas Llosa resaltan - simultáneamente- el infantilismo y el esperpento de los comportamientos sexuales humanos; la ironía y el humor; el eufemismo como retórica; etc.

En el contexto latinoamericano, además, el sexo sirve también para hacer un diagnóstico acertado de la realidad social y política de aquel continente sometido a tantos vaivenes históricos. «Así, para Vargas Llosa», argumenta Olga Caro (1990: 179), «más que un simple síntoma, la sexualidad es verdaderamente el síndrome de una sociedad. Mecanismo humano auténtico, el sexo es el indiscutible testimonio de una estructura política». El sexo, en efecto, muestra a la vez la tragedia y la farsa que encierran los estamentos militares, los burgueses acomodados, los niños y los viejos, las pobres gentes, el paisaje humano todo de países como Perú. A Vargas Llosa le desagrada la cruda realidad de su país, y la visión tragicómica que proporciona el telescopio del sexo ayuda a hacer dicha realidad algo más soportable. En todo caso, Vargas Llosa ha declarado expresamente que «sin erotismo raramente hay gran literatura. $\mathrm{Y}$ al revés, una literatura que es sólo erótica difícilmente llega a ser grande» (Vargas Llosa 200I).

En la extensa obra de Vargas Llosa, detectamos tanto la presencia constante de la sexualidad como también de la fabulación erótica explícita. Si en Pantaleón y las visitadoras (1973) el sexo es un principio gozoso que sirve de organizador estético y de fuente inagotable de comicidad, en La tía Julia y el escribidor (1977) el sexo está omnipresente, desde la tierna pasión amorosa entre tía y sobrino, hasta los cómicos excesos de otros personajes secundarios. En ambas novelas la presencia del amor y el sexo es fundamental, y afecta tanto al estilo como a los personajes. Sin embargo, en Elogio de la madrastra (I988) y en su continuación, Los cuadernos de don Rigoberto (1997), creemos que Vargas Llosa da un paso más y trata de construir una larga reflexión paródica sobre el discurso erótico. Ambas novelas nos sugieren, en ocasiones, la farsa erótica, en otras un ensayo tedioso sobre sexualidad y escritura, y aun en otras unos tímidos apuntes pornográficos. En definitiva, la sexualidad humana, en todas sus variantes, con gran diversidad de matices, se ha adueñado de la producción novelística de Vargas Llosa.

Otra cosa es la recepción crítica de dicho esfuerzo novelístico. Elogio de la madrastra, por ejemplo, ha provocado lecturas bien dispares. Mientras que Caro (I990) la califica de obra narrativa 'débil' y Béjar destaca el «desinterés académico» (I993: 243) con que ha sido acogida, para Sylvia G. Carullo (1993: 157), la obra es «un acabado logro de la representación de lo erótico». Quizá sea ésta la propia sustancia de lo erótico: la capacidad de convocar ideas, reacciones o vivencias opuestas. El Elogio puede ser leído bien como novela erótica o como novela metaerótica. Es, a la vez, una novela para gozar y un gozo novelado. Hernán Sánchez (1994: 315) abunda más en esta idea, cuando afirma 
que en dicha novela aparecen conjugados, y de manera simultánea, un erotismo de raíz cultural y un culturalismo de tendencia erótica. Con la conciliación de ámbitos tan opuestos aparentemente, se desmitifican la "pureza» estética del objeto de arte, la beatitud e inocencia infantiles, y las audacias psíquicas de una experimentación erótica insaciable.

Keith M. Booker (1994) ve en el Elogio la presencia del discurso del sexo como eje para fabular todo lo humano, que se manifiesta tanto en la pornografía explícita, en la sugerencia sensual, en el sexo como eufemismo o la pasión religiosa. El Elogio es también, para Booker, una defensa desinhibida, por parte de Vargas Llosa, del uso del discurso sexual para atraer la atención de los lectores, como ingrediente novelístico de primer orden. Se podría argumentar a favor o en contra de la ética de este proceder, pero en esta obra Vargas Llosa defiende sin ambages la concepción de la literatura como 'estimulante erótico' (Booker I994: I77).

\section{VARGAS LLOSA TRADUCIDO AL INGLÉS: EL TRATAMIENTO DEL AMOR Y EL SEXO}

En este artículo prestaremos atención a la variada gama de recursos con que Vargas Llosa construye su peculiar universo erótico (el uso de diminutivos o de palabras tiernas; la presencia de la ironía y una retórica burlona; la elaboración del erotismo como poesía, etc.) y discutiremos las soluciones adoptadas por los diversos traductores que se han enfrentado a dichas novelas (Gregory Kolovakos \& Ronald Christ, Helen Lane, Edith Grossman). En verdad, nos interesa muy parcialmente si las traducciones son buenas o malas; y nos interesa mucho más si hay, o no hay, o en qué grado lo hay, un esfuerzo por ajustarse a las sinuosidades del lenguaje sexual. Una dificultad sobrevenida es que algunas de las obras de Vargas Llosa, como Elogio de la madrastra, son difíciles de analizar o valorar, pues en gran medida constituyen ensoñaciones sobre el deseo, sobre el amor y el enamoramiento, sobre el sutil veneno del erotismo. En este caso, además, la traductora (Helen Lane) traza una traducción muy ajustada y apegada a la letra del original, tratando de mantener el mismo grado de abstracción que en el original.

Creemos que la traducción de los episodios amorosos o de las sugerencias sexuales no se rigen por criterios de verdad o de adecuación gramatical, sino de efectividad estética, cultural, ideológica. Me da la impresión de que en la traducción de la sexualidad no puede haber traducciones 'neutras', pues el material a trasladar a otra cultura es muy sensible (Simms I997) y constituye el crisol de nuestros prejuicios y nuestros tabúes más profundos. Trataré, pues, de centrarme selectivamente en aquellas soluciones inglesas en que se ha modificado el tratamiento dado al lenguaje del amor y del sexo por Vargas Llosa en las cuatro novelas mencionadas.

\section{I. El sexo como juego: galanterías y diminu- tivos}

En Vargas Llosa, el amor y la sexualidad son poliédricos, presentan múltiples rostros, diversos grados de elaboración literaria.

Una de las dimensiones que podemos destacar es esa visión, tan vargallosiana, del amor como algo tierno, infantil, inocente. La fuerza del sexo y de la seducción nos llega a través de diminutivos y de requiebros, de palabras tiernas y de galanterías. Es éste un aspecto muy importante en la escritura del autor limeño, pues sirve para darle un toque lírico y juguetón, lejos de las estridencias del amor apasionado. A menudo parece que lo que en Vargas Llosa es elabora- 
ción pausada, en la traducción inglesa es opción sin matices, ligeramente sexualizada, que llega a transmitir una concepción negativa del amor.

En La tía Julia y el escribidor, la tía Julia, mujer madura y que ha tenido una relación matrimonial con anterioridad, se lamenta de que a las mujeres divorciadas todos los hombres se creen con derecho a acosarlas sexualmente, con requiebros o proposiciones indecentes. $\mathrm{Y}$ añade la tía Julia:

No te enamoran, no te dicen galanterías finas, te proponen la cosa de buenas a primeras con la mayor vulgaridad. (TJ 29) ${ }^{2}$

They don't flirt with you, they don't whisper sweet nothings in your ear. They just come straight out with what it is they want from you, right off the bat, in the most vulgar way imaginable. (TJ I2)

La traducción inglesa de 'enamorar' y 'galanterías finas' es bastante libre, y tanto 'flirt with you' o 'sweet nothings' nos transmiten una imagen negativa del amor como juego de seducción. En español, hay pausa y delectación; en inglés, hay inmediatez, mera relación física, prejuicio.

En otro ejemplo de la misma novela, el autor pone en boca de Gumercindo Tello, personaje esperpéntico que ha violado a Sarita Huanca Salaverría, $\left(\S_{2}\right)$ «piropos de mal gusto e insinuaciones intrépidas» (TJ I63), que, dado el calado del personaje a que se refieren, sorprenden por su tibieza. La traductora, Helen Lane, parece haber querido compensar esta aparente incoherencia, al traducir «paying her indecent

2 En adelante, para referirnos a las obras de Vargas Llosa, utilizaremos las siguientes abreviaturas: PV (Pantaleón y las Visitadoras), TJ (La tía Julia y el escribidor), EM (Elogio de la madrastra) y CR (Los cuadernos de don Rigoberto). compliments or making bold advances» (TJ I03). Este pasaje ofrece una mezcla bien curiosa: por un lado, sobresexualiza el original; y por otro, transforma el $\left(\$_{3}\right)$ «estupro» ( $\left.\mathrm{TJ} \mathrm{I}_{3}\right)_{3}$ que sufre Sarita, una categoría jurídico-moral, en «her defloration» (TJ IO3), un término meramente físico, casi idílico.

Otros términos en Vargas Llosa, galantes y abstractos, resultan sobresexualizados en las traducciones. En Elogio de la madrastra y Los cuadernos de don Rigoberto, hay momentos en que todo parece una ensoñación romántica, como cuando de Lucrecia se nos presentan $\left(\S_{4}\right)$ «sus formas blancas, ubérrimas» (EM I6) - que en inglés podemos leer como «the full white curves of her body» (EM 4) - o la propia Lucrecia rememora alguno de sus gestos románticos con la expresión $\left(\$_{5}\right)$ «una pequeña coquetería» (CR 65) - traducido como «flirted with him just a little» (CR 37). En ambos casos se incrementa sutilmente el grado de sexualización de los originales, y nuevamente se acentúa una concepción del amor que se nos antoja peyorativa.

Junto al uso de galanterías para dibujar el amor como una forma de romanticismo algo abstracto, Vargas Llosa utiliza con maestría el diminutivo. El diminutivo suele actuar como eufemismo, y añade un tono emotivo, casi infantil, a los ritmos del amor. Pantaleón y las visitadoras es el reino del eufemismo, pueril pero corrosivo; es una deliciosa obra que lleva el eufemismo al extremo del humor, muy a menudo desinhibido e intranscendente. En un pasaje delicioso, Pochita envía una carta a su hermana y le relata con sumo gracejo, pero con absoluta contención lingüística, confidencias acerca de los comportamientos amorosos que observa en Iquitos, incluidos los de su propio marido, Pantaleón Pantoja. Hemos seleccionado unos breves fragmentos: 


\section{(\$6)}

imaginársela haciendo cositas con el mamarracho ese, vaya depravada y él peor. (PV 69)

imagining her making it with that clown, she's depraved and he's worse. (PV 49)

\section{$(\$ 7)$}

¿no decía todo el mundo que el marido de la Pulpito Carrasco se volvió locumbeta de tanto hacer cositas con ella? (PV 70)

Didn't everybody say that Pulpito Carrasco's husband went out of his head from doing it so often with her? (PV 50)

Imagínate que la otra noche lo chapé tomando tiempo con un cronómetro mientras hacíamos cositas, se lo dije y se confundió muchísimo. Después me confesó que necesitaba saber cuánto duraban las cositas entre una pareja normal: ¿se estará volviendo vicioso? (PV 7I)

Picture this, the other night I caught him with a stopwatch timing how long our business took us. I asked him about it and he got very confused. Later he confessed to me he had to know how long a little business like that took for a normal couple. Do you think he's turning into a pervert? ( $\mathrm{PV} 5^{\mathrm{O}}$ )

\section{(§9)}

¿hacían cositas cositas en plena película, en esa incomodidad y con el susto de que los pescaran? (PV 77)

they did business business in the middle of the movie, so uncomfortable and afraid of being caught? (PV 56)

Se creyó que éramos unos degenerados, que yo la había hecho entrar para que hiciéramos cositas los tres juntos. (PV 80)

She thought we were some degenerates, that I had made her come in so the three of us could do a little business together. (PV 57)
Estos fragmentos proceden de un largo capítulo en que abundan los diminutivos, que transmiten con fidelidad el calor que hallamos en el amor humano, y al mismo tiempo la pequeñez, el esperpento y la comicidad presente en todo acto erótico. Lo que en español («hacer cositas») es eufemismo infantil y gozoso, en la traducción inglesa no encuentra acomodo, quedando transformado en verbos vacíos, en frases neutras («making it», «doing it», «our business», «did business business», «do a little business»). La carga sexual queda presente en versiones más neutras y formales, pero menos coloristas. Los diminutivos españoles son, sin duda, muy difíciles de resolver en inglés, pues la dimensión emotiva (y moral) que aportan queda habitualmente desdibujada en las traducciones.

Podemos añadir otros ejemplos del uso del diminutivo como estímulo entre infantil y obsceno, entre emotivo y pecaminoso. En Pantaleón, la Brasileña, una de las visitadoras, trata de hacer un favor a Pantaleón Pantoja, al ver que (§II) «tenía la bragueta hinchadita» (PV I37). La traducción («I made your pants puff up» PV IO2), además de posiblemente incorrecta, ignora el delicioso ejemplo de contención lingüística para describir el deseo sexual extremo. El bello, irónico, inocente diminutivo desparece en medio de una frase meramente descriptiva.

El diminutivo sirve, por tanto, para trasladar, a través del eufemismo y la emotividad, innumerables referencias a los órganos sexuales -en

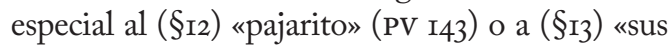
cositas» (CR 278)- a las caricias sexuales - (\$I4) «bocaditos» (CR I73) - o a las variadas formas de actividad sexual - $-\left(\S_{15}\right)$ «La cornetita, el sandwichito, el chiquito» (CR 376). Las traducciones de estos términos siguen siendo formalmente correctas, pero desprovistas de la emotividad y la comicidad de los originales: «your little dickie» (PV IO6), «their things» (CR I62), «appetizers» (CR 
IOo), «Blow-jobs, the sandwich, up-the-ass» (CR 216). Este último ejemplo, en concreto, podría hallarse con suma facilidad tanto en un manual de sexología como en una revista pornográfica. En Pantaleón, el General Scavino, casi al final de la novela, cuando todos parecen haberse librado de la eficiencia febril del capitán Pantoja, se desabotona la bragueta y solicita de la Peludita (§I6) «unos cariñitos» (PV 302). Nuevamente la traducción («a little affection» PV 240) se pierde en una neutralidad asexual, destruyendo el efecto obsceno del original.

Para terminar, mención especial merece el uso del diminutivo 'potito' en Los cuadernos de don Rigoberto. Dos ejemplos bastarán:

'Pero, papi, por favor, que tus amigos, si me hacen cariños, no me los hagan en el potito.' (CR I78)

'But, Papá, please, if your friends want to hug me, tell them not to touch my bottom. (CR IO4)

(§ 18$)$

'- Me estás tocando el potito, pues, igual que los amigotes de mi papá y los curas del colegio. ¡Qué les ha dado a todos con mi pompis, caramba!' (CR I9I)

'You're touching my backside too, just like my papa's friends and the priests at school. Golly! Why is everybody so interested in my bottom?' (CR III)

En estos fragmentos, y en otros en Los cuadernos, hay una cierta disonancia entre las formas infantiles 'potito' y 'pompis' que utiliza Fonchín (o Alfonso) y la propia maduración sexual del adolescente. Hay todo un espacio entre lo decible y lo no decible, entre lo (social y sexualmente) aceptable y lo no aceptable, que sitúan esta obra en los límites sobre la reflexión moral sobre el erotismo. Las referencias, ade- más, a los 'amigotes' — concepto casi imposible de traducir-y a los 'curas del colegio', sugieren una tradición de concupiscencia, de represión, de gestos ambiguos. La pederastia como límite moral está flotando en este libro. Las traducciones inglesas, muy académicas, destruyen parte de este universo moral.

\subsection{El sexo como acción: ¿̇quién y cómo?}

En las obras de Vargas Llosa que hemos analizado hay toda una constelación de personajes que viven en torno al sexo, que se enamoran y que sufren desengaños, que son seres inocentes o perversos pero que, sobre todo, hablan incesantemente sobre la seducción, el amor, la sexualidad, el erotismo, las perversiones. Destaca, en primer lugar, una galería de personajes que viven la sexualidad como patología, como deficiencia, como exceso, como vicio.

En Vargas Llosa los personajes más visibles son aquellos que viven el sexo como desviación. Pantaleón y las visitadoras nos ofrece una buena nómina de dichos personajes. Para empezar, uno de sus grandes logros es el término (\$Ig) «Visitadoras», que aparece repetido a lo largo y ancho de todo el libro, y que con tanta economía, sencillez y belleza gráfica, recoge un concepto duro, difícil, que tanto rechazo social provoca. Todo Pantaleón es una fabulación, entre onírica y esperpéntica, sobre un microcosmos regulado, con eficencia militar, en torno a la sexualidad humana. Dada la densidad emocional y la admirable simplicidad del concepto, los traductores al inglés (Gregrory Kolovakos y Ronald Christ) utilizan diversos términos, en especial el término «specialists» (PV I5) - O «Special Service» (PV I5) para traducir «Servicio de Visitadoras» - y ocasionalmente «female recruits» (PV 76) e incluso «women» (PV 77).

Donde más se resiente la traducción al inglés es, quizá, al trasladar aquellos términos que abun- 
dan en español ('pendejo', 'marica', 'perica', etc.) y que suman una connotación sexual a una valoración moral peyorativa. En el siguiente ejemplo:

132

Hay violaciones a granel y los tribunales no se dan abasto para juzgar a tanto pendejón. Toda la Amazonía está alborotada. (PV I2)

There are rapes all over the place and the courts can't handle them all. The entire Amazon District is up in arms. ( $\mathrm{PV} 4$ )

se ha omitido clamorosamente el término 'pendejón', forma aumentativa de 'pendejo's, que hace referencia a un conjunto de significados que van desde del apelativo despectivo para aquellos adolescentes que se creen adultos, o para indicar 'tonto' o ‘torpe', o también 'juguetón' o 'travieso'. En todo caso, la traducción inglesa suprime sin más la calificación moral presente en el original, y transforma la violación en un hecho despersonalizado, sin culpables. La traducción ha despenalizado la violación, desplazando su culpa de los violadores - esos 'pendejones' a que tan cariñosamente se refiere el original- a las propias violaciones, cual si fueran entes abstractos. La misma tibieza al calificar moralmente a algunos personajes aparece nuevamente casi al final de Pantaleón y las visitadoras, cuando el general Tigre Collazos amonesta - y, al mismo tiempo, admira sexualmente - al capitán Pantoja:

$(\S 2 \mathrm{I})$

- Creíamos que no mataba una mosca y resultó un pendejo de siete suelas, Pantoja (PV 3OI)

«We thought you couldn't kill a fly and it turned out you were a downright wheelerdealer,» (PV 239)

3 'Pendejo' significa «I Pers. de vida licenciosa. A veces la forma $m$ designa indistintamente hombre o mujer. [...] 2 Sinvergüenza» (Seco et al 1999: 3464).

Lo que quizá debiera ser tomado como un insulto, o una amonestación moral, más parece, en la novela, y aun en muchas situaciones reales, un homenaje a la valentía, al coraje, a la hipersexualidad masculina - que, curiosamente, aunque no puede ser objeto de alabanza pública, sí constituye motivo de orgullo varonil. El término 'wheeler-dealer' no parece recoger las connotaciones licenciosas y sexuales de 'pendejo'.

En otro pasaje de la misma novela, aparece una referencia a $\left(\$_{22}\right)$ «un marica que le dicen Milcaras» ( $\mathrm{PV} \mathrm{I}_{3}$ ), que en inglés se lee como «some queer they call Chameleon» (PV 5). 'Marica' puede ser un insulto muy fuerte en español, pues en él confluyen estereotipos de género y la estigmatización social de las identidades sexuales alternativas. Quizá el término inglés 'queer' no es la mejor opción, pues, si bien es cierto que es usado despectivamente por muchas personas, también está siendo sometido a un importante proceso de dignificación léxica (vid. Cameron \& Kulick 2003).

En la carta que Pochita escribe a su hermana Chichi, aquélla relata ofendida, y con patente desprecio, que vio a su marido Pantaleón Pantoja en compañía de una mujer, Chuchupe, que regenta una casa de citas, y a quien califica así:

$(\S 23)$

una perica tan llena de pintura que no le cabía una gota más ni en las orejas, con unas teteras y un pompis que rebalsaban del asiento, (PV 68)

the woman so covered with make-up there wasn't room for a drop more, not even on her ears, with such tits and an ass spilling over the chair, (PV 48)

$(\$ 24)$

La perica es la mujer de más mala fama de todo Iquitos, el enemigo número uno de los 
hogares, le dicen Chuchupe y tiene una casa de pes en la carretera a Nanay, (PV 69)

The woman decked out like a parrot has the worst reputation in all Iquitos, Enemy Number One of home life, they call her Chuchupe and she has a brothel on the road to Nanay, (PV 49)

El término 'perica'4 trasluce un ánimo ofensivo por parte de Pochita, que se siente herida por las compañías que frecuenta su marido. Introduce una nota de reprobación moral y de sexualidad desordenada que desaparece completamente en la traducción ('the woman'). Censura moral que también aparece, mezclada con la comicidad, cuando el capitán Mendoza le señala al capitán Pantoja los estragos que provoca la selva andina en la libido de los hombres allí destacados:

Todos los pingalocas del pueblo amontonados alrededor del campamento. Mira allá, ¿los ves? (PV 228)

All the town's stiff dicks jammed together around the camp. Look over there. See 'em? (PV I7I)

Expresión muy gráfica, 'pingalocas' vuelve a incidir en el sexo masculino como activo (frente a la pasividad femenina), como poseído de un resorte automático que lo lanza ciegamente hacia el sexo femenino. Pese a que el término supone una crítica moral, no deja de constituir un cierto reconocimiento implícito. Nuevamente, la traducción ('stiff dicks') omite esta dimensión.

Para terminar este apartado sobre los personajes que intervienen en el amor y el sexo,

\footnotetext{
4 'Perica' es una forma coloquial que indica «I (col) Mujer de vida libertina o desenvuelta. $A$ veces usado como insulto» (Seco et al I999: 3485).
}

mencionaremos una característica peculiar de la escritura de Vargas Llosa. Consiste ésta en la utilización frecuente de los términos 'macho' y 'hembra' para caracterizar al hombre y a la mujer en tanto que actores eróticos. Estos términos subrayan la animalización de ambos, así como una visión despectiva, objetual. Ambos términos llevan años en el centro del debate en torno a una representación respetuosa de las personas en el lenguaje5. Para muchos son síntoma de otra época, de una visión estereotipada de los sexos, con los roles bien definidos: con el 'macho' de la especie dominando a la 'hembra' —objeto pasivo, cuya única función en la vida se sitúa alrededor de la sexualidad y la reproducción-, sometiéndola, y siendo 'inflamado' por sus deseos sexuales más primitivos, que han de ser satisfechos obedientemente por las mujeres. La concepción de la sexualidad que, muy a menudo, Vargas Llosa transmite es profundamente sexista y tradicional. Esta «moral machista» (Berg I998: 65) o esta «visión falocéntrica esencializante de la mujer» (Béjar I993: 253) queda enterrada en la traducción, que opta por términos más neutros como 'man', 'woman' o 'wife'.

También merecen un breve comentario los actos relacionados con el sexo. $\mathrm{Y}$ aquí Vargas Llosa despliega también una enorme variedad de estilos y sugerencias. Junto a algunos términos concretos y vulgares, abundan los eufemísticos, y también podemos rastrear una importante dimensión poética y algún que otro experimento lingüístico. Unos pocos ejemplos bastarán. En Pantaleón y las visitadoras, en una conversación acerca de la posible ampliación del Servicio de Visitadoras, el teniente Bacacorzo,

5 De hecho, hace unos años los términos 'macho' y 'hembra' se hallaban en toda documentación administrativa, pero desde hace unos años se han eliminado casi por completo. 
en conversación con el capitán Pantoja, fantasea acerca de que $(\$ 26)$ «la selva se convertiría en un solo bulín y usted, en su oficinita del Itaya, tomaría el tiempo de ese diluvio de polvos con un millón de cronómetros» (PV I45). Lo que en español es concreto y vulgar ('ese diluvio de polvos') queda convertido en inglés en referencia abstracta («that flood of semen», PV I08). La figura es una exageración pues constituye, como todo Pantaleón, una hipérbole sexista, que privilegia el punto de vista del deseo masculino. Ya vimos igualmente como un término como $\left(\$_{3}\right)$ «estupro» (TJ I63), categoría jurídica y moral, acaba convirtiéndose en «her defloration» (TJ Io3), término que parece sacado de un novelón sentimental.

En bastantes ocasiones, predomina en el estilo de Vargas Llosa una retórica basada en el eufemismo, mecanismo lingüístico que «permite nombrar un objeto no con la palabra que literalmente lo designa, sino con otra que parece socialmente más conveniente» (Chamizo \& Sánchez 2000: 25). En Pantaleón y las visitadoras, el coronel López López menciona la expresión $\left(\$_{27}\right)$ «haciendo vida marital» (PV I7), que en inglés queda como «carrying on like a newlywed» (PV 8). Curiosamente, la opción inglesa resulta aún más eufemística, si cabe, que el original. El eufemismo - y sobre todo el esfuerzo eufemístico continuado- requiere un gran tacto, ya sea como escritor o como traductor. En La tía Julia y el escribidor, leemos acerca de Alberto de Quinteros, marido ejemplar que no aprovecha $(\$ 28)$ «su momentánea soltería para echar algunas canas al aire» (TJ 38), que tiene - una vez más en Vargas Llosa- ese tono de amable condescendencia y de suave crítica moral que sólo merecen los hombres. La traducción, nuevamente, diluye la tenue censura del original, y la deja en un insustancial «to have himself a little fun» (TJ I8).
En muchos pasajes de Elogio de la madrastra apreciamos un notable esfuerzo por acuñar una visión poética sobre el erotismo. Se utilizan términos abstractos, de gran resonancia y densidad conceptual, y se usan renovadas imágenes para hablar del amor y el sexo. Lucrecia, la madrastra, fantasea y poetiza su imaginada relación con Fonchito, con estas palabras:

$(\$ 29)$

Sin habernos tocado ni cruzado palabra, nos hemos hecho gozar innumerables veces (EM 74)

Without having ever touched each other or exchanged a single word, we have brought each other to the heights of rapture countless times (EM 50)

La sencillez poética del original se transforma, en la traducción inglesa, en una frase compleja, académica, excesiva. Y lo mismo ocurre con alguno de los apuntes metaeróticos generados por las pinturas intercaladas en la novela, esos apuntes cuya función «consiste en entonar, a su modo, el "elogio de la madrastra", es decir, la apología del erotismo» (Berg ı998: 67). Y, sobre el fondo de un cuadro surrealista de Francis Bacon, se habla de la seducción, de la voluptuosidad, de los refinamientos del amor, y se prodigan imágenes como, por ejemplo, (\$30) «trenzarse conmigo sobre una cama» (EM I23), cuya traducción inglesa es «to do amorous battle with me on a bed» (EM 9I). Nuevamente, simplicidad y lirismo frente a elaboración y complejidad retóricas.

Las relaciones entre Lucrecia con Don Rigoberto y su hijo nos proporcionan también ejemplos de discrepancias entre el original vargasllosiano y la traducción inglesa. Como culminación del primer episodio amoroso entre Lucrecia y Don Rigoberto, se describe a la madrastra en medio de un torbellino de placer, 
(§3I) «rumiando palabras que apenas podía articular, hasta sentir que fallecía» (EM 23). Así concluye la primera relación sexual entre ambos, con una admirable economía expresiva. La traducción inglesa, por contra, prefiere la expansión léxica: «mumbling words just barely articulated, till she felt herself dying, fainting, failing» (EM II). ¿A qué responde este exceso, este juego fónico in crescendo? En la relación que mantienen Lucrecia y Fonchito, la consumación sexual es también un prodigio de economía expresiva:

Lo había sentido, muy poco después, soltando un gemido, terminar. (EM I45)

Very soon thereafter, she had heard him let out a moan as he came. (EM rog)

Se pierde otra vez, en la traducción inglesa, el delicado equilibrio que mantiene Vargas Llosa entre la urgencia de la experiencia erótica y la extremada contención del lenguaje literario. Cuando la reflexión erótica se torna pura experimentación formal - $\left(\$_{33}\right)$ «traumatizando la sintaxis: yo te me entrego, me te masturbas, chupatemémonos» (EM I6I)—, la traducción se vuelve imposibilidad ontológica - «traumatizing syntax: I give yourself to me, you masturbate myself for you, let's you and me suck our selves» (EM I2I). Cada lengua (re) escribe el amor y el sexo siguiendo sus propias coordenadas vitales.

\subsection{El sexo como eufemismo: ironía y retórica burlona}

Observamos que la comicidad en Vargas Llosa procede, con frecuencia, del eufemismo, de las medias palabras, de lo no dicho. El eufemismo y la ironía son formas de transgredir las reglas lingüístico-sociales, de decir y no decir (véase Santaemilia 2005), de liberar el discurso de sus ataduras públicas. La comicidad resultante se suele centrar en aquellos personajes deficientes, marginales, que representan la sexualidad como desviación. En la actividad sexual hay circunstancias indeseables, comportamientos inadecuados, experiencias no verbalizadas. Y para transmitirlos al lector, intervendrá decisivamente el eufemismo, de la mano siempre de la ironía. Véase, como ejemplo, en Pantaleón y las visitadoras, las palabras de Paiva Runhuí, alcalde de un pueblo de la selva amazónica, cuando solicita el amparo del ejército para que terminen los atropellos sexuales de los soldados:

\section{(\$33)}

- Me perjudicaron a una cuñadita hace pocos meses y la semana pasada casi me perjudican a mi propia esposa. ( $\mathrm{PV} \mathrm{I}_{2}$ )

«Just a few months ago they molested my dear sister-in-law and last week they almost raped my own wife.» (PV 4)

'Perjudicar' es término ambiguo, y al tiempo irónico, para referirse a la lacra de las violaciones en territorio de la selva. Nuevamente, en Vargas Llosa, observamos una mirada amable sobre los comportamientos sexuales desordenados de los hombres. La traducción es desigual: mientras 'molested' podría incluir una gama imprecisa de abusos sexuales, 'raped' es definitivo y rotundo. Este último verbo rompe todo efecto de incertidumbre y de especulación irónica. Hay en la traducción inglesa — quizá sea consustancial a toda traducción - un deseo por explicitar, por contextualizar, por desambiguar. Lo mismo sucede en otros ejemplos, como cuando la 'Brasileña', visitadora de la que se ha encaprichado el capitán Pantoja, le dice que $\left(\S_{34}\right)$ «Estoy con mi cosa, señor Pantoja, me vino ayer justamente (PV I36). 'Mi cosa' es una expresión vacía, pero perfectamente comprensible, que pierde 
resonancia si se la hace más explícita («It's my time of the month, Mr. Pantoja, it came just yesterday», PV Ior). Y aún otro ejemplo: en las largas epístolas que Chachi recibe de su hermana Pochita, ésta se muestra con los nervios alterados, aunque $\left(\$_{35}\right)$ «en realidad no debería estarlo, quiero decir por el lado de los cuernos y de la infidelidad» (PV 70), expresión redundante pero muy gráfica. Los cuernos son emblema y símbolo del cornudo - es decir, el marido cuya esposa le es infiel- $y$, por extensión, de toda infidelidad. Una traducción como «tomcatting and cheating» (PV 50) destruye toda una tradición cimentada en la literatura, la psicología o el refranero popular.

Un ámbito que da mucho juego, sobre todo en Pantaleón y las visitadoras, es el de la prostitución, uno de los ejes de dicha novela. En efecto, la prostitución es, a un tiempo, lacra social y gozosa recreación literaria. Hay una mirada condescendiente sobre las vidas y los destinos de las 'visitadoras' pero hay también, sobre todo, una glorificación del deseo (animal) masculino. El teniente Bacacorzo relata el caso de Luisa Cánepa, su sirviente, que fue violada por un sargento, por un cabo y finalmente por un soldado raso. Pese a la gravedad moral y legal del hecho, el relato del teniente prosigue así:

\section{$\left(\S_{36)}\right.$}

- La cosa le gustó o qué sé yo, mi comandante, pero lo cierto es que ahora se dedica al puterío con el nombre de Pechuga... ( $\mathrm{PV}_{13}$ )

«She must have liked it or something, Commander, but one thing we can be sure of now is that she's turned into a prostitute by the name of Knockers ...» (PV 5$)$

'Puterío' es un término vulgar, despectivo, que hace referencia tanto al colectivo de prostitutas como a la prostitución en sí. La solución

inglesa opta por transformar lo colectivo en concreto ('a prostitute'), como ocurre también en la referencia del teniente Bacacorzo a $\left(\$_{37}\right)$ «los sitios putañeros de Iquitos» (PV 27), que ha sido trasladado al inglés como «the red-light districts of Iquitos» (PV I6). En un estilo totalmente opuesto, el capitán Avencio P. Rojas, en carta oficial al comandante Godofredo Beltrán, hace referencia a $\left(\$_{3} 8\right)$ «los medios prostibularios de Iquitos» (PV II2), que es traducido al inglés como «the brothels of Iquitos» (PV 82). En todos los casos, vemos que el colorido y la fuerza expresiva se han perdido a cambio de una referencia más ajustada y concreta.

La inefable Pochita, en referencia a la madama Chuchupe, indica que ésta (\$39) «tiene una casa de pes en la carretera a Nanay» (PV 69). Vemos aquí un uso, entre cariñoso y cómico, del eufemismo 'casa de pes' para referirse a lo que en inglés leemos como «brothel» (PV 49), es decir, burdel. Siendo los significados idénticos en ambos textos, en español resulta más gráfico, inmensamente más evocativo. Es un procedimiento análogo al del inglés f-word, que indica aquellas palabras que, en su mayoría, comienzan por $\mathrm{f}-\mathrm{y}$ que son términos tabú. Es ese juego, tan habitual con las referencias sexuales, de decir y no decir. Lo que sorprende en la traducción inglesa es que, unas páginas más adelante, se prefiera mantener la ambigüedad y el juego lingüístico:

(§40)

Sí, Chichi, ¡era una pe, una pe!, las «lavanderas» de Iquitos son las pes de Iquitos y van de casa en casa ofreciendo sus servicios con el cuento de la ropa. (PV 79)

Yes, Chichi, she was a w---. A w---! The «washerwomen» of Iquitos are the w---s of Iquitos and they go around from house to house offering their services with that story about laundry. (PV 57) 
En todo caso, parece evidente que la comicidad se pierde si hay una excesiva explicitación (o desambiguación) de los eufemismos. Los eufemismos son efectivos en tanto que siguen siendo eufemismos; lo que se modifica con la desambiguación no es tanto el significado (que ya estaba claro desde el principio) sino el placer primario del juego lingüístico. Suele ocurrir que las traducciones muchas veces se centran en el sentido a expensas de la experimentación lingüística, en las formulaciones inequívocas a expensas de las ambiguas. En La tía Julia y el escribidor, la tía Julia se lamenta de que su tía Hortensia y su tío Alejandro, como forma de castigarla por su repentino matrimonio con el joven Mario, ni la saludaron el día anterior, y que, además, $\left(\S_{4} \mathrm{I}\right)$ «sólo les faltó decirme pe». La solución que da Helen Lane es perfectamente comprensible, quizá demasiado comprensible: su opción «I wouldn't have been at all surprised if they'd call me a whore to my face» nos parece excesiva, sin ese leve matiz del sexo prohibido como juego. Otro ejemplo, de Los cuadernos de don Rigoberto, nos servirá para acabar de mostrar nuestro argumento. En uno de sus soliloquios sexuales, en que fantasea sobre Lucrecia, Don Rigoberto manifiesta que $\left(\S_{42}\right)$ «no he efectuado otros disparos que los seminales, que, a ellos sí, reivindico con orgullo patriótico» (CR 292). Lo que es expresión figurada, metáfora obscena con gran poder de evocación, queda transformado en la traducción de Edith Grossman, en descripción casi médica (o pornográfica): «[I] have shot off nothing but semen, ejaculations to which I make claim with patriotic pride» (CR I7O).

\subsection{El sexo como dimensión moral}

Las novelas de Vargas Llosa muestran una preferencia por representar los elementos negativos del amor y el sexo: la sexualidad, como afirma Olga Caro (1990: 170), «se deforma y exhibe sus rostros monstruosos para dar testimonio de los males de una sociedad, es decir, del determinismo social, de la violencia, de la frustración, de la corrupción y de la hipocresía». Podemos, pues, reconocer en Vargas Llosa una dimensión moralizante que está presente en prácticamente todas sus obras. Muchos de sus personajes son seres deficientes, que viven la sexualidad como engaño o como espejismo.

Una fuente básica de injurias y de insultos es la inadecuación sexual masculina. Términos como 'carajo', 'conchudo' o 'maricón' son algunas de las metáforas que con mayor facilidad podemos identificar con el mundo de las novelas de Vargas Llosa, que frecuentemente es un universo masculino profundamente sexista. Pantaleón y las visitadoras es una cifra de dicho mundo. En una de las pesadillas del capitán Pantoja, exclama:

\section{$\left(\S_{43}\right)$}

- ¡Desabrocharse las camisas, so carajos! (PV 54) «Unbutton your shirts, damn it!» (PV 37)

Y el general Tigre Collazos apostrofa:

$\left(\S_{44}\right)$

- Vaya conchudos, antes protestaban porque la tropa se tiraba a sus mujeres y ahora porque les hacen falta mujeres para tirarse (PV I44)

«Damn these idiots. Before they were protesting because the troops were throwing themselves at their women, and now they're complaining because they don't have women to throw themselves at,» (PV 107)

Son palabras que se escuchan constantemente, que denotan un lenguaje coloquial y también un comentario moral paralelo. Se valen 
de la eufonía de estas palabras prototípicamente masculinas para resaltar alguna suerte de inadecuación. Aportan al texto, no tanto un signifi138 cado concreto, cuanto una valoración moral. La traducción inglesa es en ambos casos 'damn (it)', que reproduce adecuadamente la intención del original, pero omite la relación con la sexualidad masculina. En La tía Julia y el escribidor, el Dr. Rebagliati amonesta a Pedro Camacho y le dice: $\left(\S_{45}\right)$ «- No sea avaro, carajo ${ }^{6}$, gástese los cuatro cobres que vale un ómnibus y llegue a los sitios a la hora debida» (TJ 555), que igualmente es traducido por «damn it» (TJ 368$)$.

Dada su profusión lingüística, la mayor fuente de calificativos morales procede quizás de la homosexualidad masculina. Los términos 'maricón' (generalmente como insulto) y 'mariconería' (tanto en sentido propio como figurado), aparecen una y otra vez en las novelas de Vargas Llosa. En Pantaleón y las visitadoras, el general Scavino insulta al capitán Pantoja: (\$46) «iPantaleón, maricón, huevón!» (PV 216). En La tía Julia y el escribidor, el joven Mario rememora la severa oposición de su padre al matrimonio con la tía Julia, aunque, concede su progenitor, $\left(\S_{47}\right)$ «más terrible hubiera sido, por ejemplo, que me hubiera dado por ser maricón» (TJ 536). En la misma obra, el sargento Lituma se pregunta dónde estará el Chato Soldevilla, ese ( $\left.\S_{48}\right)$ «tumbesino mariconazo» (TJ Ioo). En todos los casos se pretende expresamente insultar, denigrar; las versiones inglesas son débiles: «queer» ( $\mathrm{PV} \mathrm{I62}$ ), «a fairy» (TJ 356) o «that chicken» (TJ 6I). Y si los homosexuales merecen el insulto, la homosexualidad (masculina) es fuente tanto de insultos como de inade-

6 'Carajo' es: «I Miembro viril. [...] 2 Vacio de significado, se emplea para reforzar o marcar la intención desp de la frase. [...] 3 Cosa fastidiosa e irritante. $4(\mathrm{reg})$ Pers. insignificante y despreciable» (Seco et al I999: 876).

cuación: (\$49) «一Déjate de mariconerías y enchúfate el capote» (TJ I26), ordena Lituma al agente Arévalo, descargando en esa palabra un sentimiento de superioridad obviamente sexualizado, que la traducción inglesa transforma en un insustancial «Stop acting like an idiot» (TJ 78). En la misma obra, Pedro Camacho, locutor boliviano de éxito, declara que los dos pecados capitales de los argentinos no son - como pudiera pensarse - la arrogancia o la cursilería, sino $\left(\$_{50}\right)$ « $[1]$ a cojudez y la mariconería» (TJ 85). La traducción inglesa recurre, como muchas veces hacen las traducciones, a una descripción prolija ( Chasing after cunt and assholing with queers» TJ 5I), que, comparada con la economía expresiva del original, suena a exceso.

Ya he dicho que el sexo es muchas veces diagnóstico de una realidad mezquina, y entonces es algo sucio y manchado, como se comprueba cuando el sargento Lituma encuentra, en la noche invernal, a un negro desnudo que $\left(\S_{51}\right)$ «no se tapaba sus cochinadas, que le bailoteaban alegremente, a la luz de la linterna» (TJ IO7). En español, esto constituye un juicio valorativo claro: el sexo como vergüenza; en inglés («his privates», TJ 66), se ofrece una opción más neutra, que evita toda valoración moral.

Normalmente, como vemos, el colorido del texto original se pierde en la traducción, que adopta formas más académicas o enciclopédicas, más descriptivas. La valoración moral del original suele desaparecer en el texto inglés. Pero hay excepciones. En una conversación con el joven Mario, la tía Julia, después de lamentar que el amor ha perdido su carácter ritual, sentencia: $\left(\$_{52}\right)$ «Qué porquería se ha vuelto el amor entre los mocosos de ahora, Marito» (TJ 30). En el mismo libro, el doctor Barreda y Zaldívar dialoga con mucho tacto con Sarita Huanca para tratar de averiguar $\left(\S_{53}\right)$ «si era cierto que Gumercindo Tello la molestaba 
desde hacía tiempo con frases maleducadas» (TJ I76). En ambos casos la traducción («What an obscene thing love has become among kids today, Marito» (TJ I3) y "whether it was true that Gumercindo Tello had bothered her for some time by making indecent remarks» (TJ II2)) añade una mirada moral que abunda en la caracterización negativa de la sexualidad.

\section{LA TRADUCCIÓN DEL SEXO EN VARGAS LLOSA: PUNTO Y SEGUIDO}

Hemos visto cómo el amor y el erotismo, fuentes básicas del edificio narrativo de Mario Vargas Llosa, presentan grandes dificultades en su traducción al inglés. Traducir el lenguaje relativo al sexo es, sin duda, un área muy sensible, el lugar de confluencia entre las interdicciones sociales y los límites éticos de cada traductor. Con frecuencia los traductores, al enfrentarse a los términos sexuales, suelen adoptar mecanismos defensivos, que incluyen el eufemismo, la ambigüedad o una gama imprevisible de autocensuras.

Las divergencias en la materialización de las referencias al amor y al sexo afectan no sólo a la correción lingüística o a la organización discursiva, sino también a la dimensión moral, a los prejuicios, a los estereotipos de un determinado grupo humano. En las páginas que anteceden, hemos comprobado cómo el sexo, que en Vargas Llosa es en ocasiones un juego galante y lírico, se transforma en su versión inglesa en elaboración más densa, más pausada, ligeramente negativa. Los diminutivos vargasllosianos, en concreto, pasan de eufemismos gozosos a opciones neutras y vacías, de las que ha desaparecido toda dimensión emotiva y moral. También hemos sido testigos de una nómina de personajes que viven la sexualidad como patología o exceso. Hay palabras ('maricón', 'pendejo' o 'perica', entre otros) que se sitúan entre la calificación moral y la connotación sexual, y que en inglés encuentran difícil acomodo, pues suelen quedar transformadas en conceptos neutros y amorales. Muy a menudo, Vargas Llosa nos transmite una moral machista o falocrática, donde se glorifica la sexualidad desordenada de algunos hombres y hay demasiada tibieza con la objetificación sexual de las mujeres. Vemos también vemos cómo la comicidad, en Vargas Llosa, procede con frecuencia del eufemismo y la ironía, en especial en obras como Pantaleón y las visitadoras, una mirada sarcástica sobre los apetitos sexuales de los hombres. Lo que llega a los lectores en lengua inglesa es un deseo por destruir el eufemismo, en aras de una mejor contextualización y explicitación. En la traducción inglesa se pierde casi toda experimentación lingüística y ambigüedad. Finalmente, analizamos el sexo como fenómeno moral, ya que muchos de los personajes de Vargas Llosa viven la sexualidad como engaño, y en las obras del autor de Miraflores se percibe un universo masculino profundamente sexista, que entroniza la hipersexualidad masculina y denigra la homosexualidad. Las versiones inglesas, casi siempre, suelen constituir opciones más académicas y objetivas, pero en ellas ha desparecido la valoración moral y la experimentación lingüística.

En este trabajo no nos interesa el 'error', pues el error forma parte tanto de la traducción como de la escritura; prefiero resaltar las discrepancias y las similitudes entre determinada concepción sobre el amor y el sexo que hay en el original y su versión inglesa. La traducción ni mejora ni empeora el texto original; quizá, en todo caso, suaviza las aristas del original para hacerla más ajustada a la nueva cultura, etc. Hemos de seguir reflexionando sobre la traducción de las referencias sexuales porque ello nos sitúa ante los límites discursivos más 
íntimos de una sociedad dada en un momento histórico dado.

$\mathrm{Ni}$ siquiera por candidez extrema parece 140 justificado esperar que la traducción haya de ser 'idéntica' al original. La traducción no es más que una de las reescrituras posibles -ideológicas e interesadas, como todas- de un texto escrito en otra lengua. De hecho, hay reescrituras que son mucho más trascendentes: la existencia o no de censura oficial, la ideología de una determinada editorial, las alianzas políticoeconómicas entre grupos editoriales, la política cultural de un determinado gobierno, la actitud social ante la diferencia y ante lo extranjero, y muchas más. La traducción de lo sexual nos sitúa ante nuestras contradicciones más íntimas, ante aquello que podemos decir y aquello que hemos de callar, ante dónde situamos los límites de lo moral, lingüística o sexualmente aceptable.

RECIBIDO EN MAYO DE 2009

ACEPTADO EN JUNIO DE 2009

VERSIÓN FINAL DE SEPTIEMBRE DE 2009

\section{REFERENCIAS BIBLIOGRÁFICAS}

\section{Fuentes primarias}

Vargas Llosa, Mario (1973). Pantaleón y las visitadoras, Barcelona: Círculo de Lectores.

Vargas Llosa, Mario (200I) [1977]. La tía Julia y el escribidor, Barcelona: Punto de Lectura, 200I.

Vargas Llosa, Mario (1978). Captain Pantoja and the Special Service, New York: Harper \& Row. Trad. Gregory Kolovakos \& Ronald Christ.

Vargas Llosa, Mario (1995) [1982]. Aunt Julia and the Scriptwriter, Harmondsworth: Penguin Books, 1995. Trad. Helen R. Lane.

Vargas Llosa, Mario (2002) [1988]. Elogio de la madrastra, Barcelona: Tusquets Editores, 2002.

Vargas Llosa, Mario (199i) [1990]. In Praise of the Stepmother, London/Boston: Faber and Faber, I99. Trad. Helen R. Lane.
Vargas Llosa, Mario (2000) [1997]. Los cuadernos de don Rigoberto, Barcelona: Punto de Lectura, 2000.

Vargas Llosa, Mario (1998). The Notebooks of Don Rigoberto, Harmondsworth: Penguin Books. Trad. Edith Grossman.

\section{Fuentes secundarias}

Béjar, Eduardo (1993). «La fuga erótica de Mario Vargas Llosa.» Symposium: A Quarterly Journal in Modern Literatures, 47/4, pp. 243-56.

Berg, Walter Bruno (1998). «Erotismo y humor en Vargas Llosa y Bryce Echenique (Elogio de la madrastra y Tantas veces Pedro)». En Karl Kohut et al (eds.) Literatura peruana hoy: Crisis y creación, Frankfurt/Main-Madrid: Verevuert/Iberoamericana, pp. 6I-72.

Booker, M. Keith (1994). «The Reader as Voyeur: Culture, Pornography, and Religion in In Praise of the Stepmothern. En Vargas Llosa among the Postmodernists, Gainsville: University of Florida Press, pp. I62-182.

Cameron, Debora h \& Don Kulick (2003). Language and Sexuality, Cambridge: Cambridge University Press.

Caro, Olga (1990). «Conceptos varguianos y sexualidad.» En Alain Sicard \& Fernando Moreno (coords.) Coloquio internacional: Escritura y sexualidad en la literatura hispanoamericana, Madrid: Centre de Recherches Lat.-Amer./Fundamentos, pp.167-180.

Chamizo Domínguez, Pedro \& Francisco Sánchez Benedito (2000). Lo que nunca se aprendió en clase: Eufemismos y disfemismos en el lenguaje erótico inglés, Granada: Comares.

Enkvist, Inger (1992). «¿Qué rasgos caracterizan una buena traducción literaria? Reflexiones basadas en traducciones de Vargas Llosa al inglés, al francés y al sueco.» Moderna Sprak, 86/2, pp. 167-75.

Robinson, Douglas (1996). Translation and Taboo, DeKalb: Northern Illinois University Press.

Sánchez, Hernán (1994). «Erotismo, cultura y poder en Elogio de la madrastra de Mario Vargas Llosa.» Anales de Literatura Hispanoamericana, 23, pp. 315-323.

Santaemilia, José (ed.) (2005). The Language of Sex: Saying \& Not Saying, Valencia: Universitat de València. 
Seco, Manuel et al (1999). Diccionario del español actual, Madrid: Aguilar. 2 vols.

Simms, Karl (ed.) (1997). Translating Sensitive Texts: Linguistic Aspects, Amsterdam/ Atlanta: Rodopi

Toledano, Carmen (2003). La traducción de la obs- cenidad, Santa Cruz de Tenerife: La Página Ediciones.

Vargas Llosa, Mario (200I). «Sin erotismo no hay gran literatura», Babelia-El País (sábado, 4 de agosto de 200I). 